\title{
Clínica, pesquisa e ensino: Nise da Silveira e as mutações na psiquiatria brasileira
}

\author{
Walter Melo*1 \\ Ademir Pacelli Ferreira*2
}

\begin{abstract}
Objetiva-se pontuar a ausência da obra de Nise da Silveira nos cânones acadêmicos. Para realçar a sua importância, propõe-se enfocar a sua obra em dois atos paradigmáticos: o primeiro, após a recusa de aplicar a ECT, a retirada de camas da enfermaria e a criação de espaço de atividades criativas e expressivas, e, o segundo, a criação do espaço externo ao hospício (Casa das Palmeiras), para casos de psicoses graves. Atos que contrapõem tanto ao clinicismo quanto à segregação asilar. Entende-se que em sua práxis, pesquisa e clínica foram indissociáveis e com forte presença do paradigma estético, o que produziu mutações na psiquiatria brasileira, ultrapassando a ideia de reforma. Conhecer seu trabalho é uma forma de contrapor a sua mitificação. Sabe-se dos limites de um artigo para analisar o legado de sua obra. Trata-se aqui de pontuar e veicular elementos escolhidos arbitrariamente e despertar interesse no seu estudo.
\end{abstract}

Palavras-chave: Nise da Silveira, clínica, pesquisa, mutações

*1 Universidade Federal de São João del-Rei - UFSJ (São João del-Rei, MG, Br)

*2 Universidade do Estado do Rio de Janeiro - UERJ (Rio de Janeiro, RJ, Br) 


\section{Introdução}

Apesar de possuir um nome sacralizado - e talvez por isso -, é surpreendente que a obra de Nise da Silveira (Nise) não tenha galgado status na academia brasileira (Carvalho \& Amparo, 2006). Mesmo os seus livros esgotados não foram reeditados. Raramente seus textos aparecem nas citações de teses e dissertações, mesmo quando estas abordam dados da história da psiquiatria e da chamada Reforma Psiquiátrica (Reforma), em que Basaglia e Laing sempre aparecem. Com as limitações de um artigo, enfatizamos que a obra de Nise apresenta diversos aspectos e se configura como uma das mais instigantes contribuições para as mutações que vêm ocorrendo na psiquiatria brasileira. Destes pode-se destacar a relação que estabeleceu com a criatividade e as artes, ao enfatizar o valor terapêutico das atividades expressivas (Silveira, 1981; 1992); a interlocução com diversos intelectuais e artistas, favorecendo para que as questões psiquiátricas ultrapassassem os estreitos limites das instituições asilares e fossem debatidos por toda sociedade - com pintores concretos (Melo, 2011a), com Rubens Correa (Melo, 2010a), com Leon Hirszman (Avellar, 2001; 2011; Melo, 2004; 2010b), dentre outros -; as pesquisas que empreendeu, questionando os pressupostos da psiquiatria (Melo, 2009b); e a criação de instituições como a Seção de Terapêutica Ocupacional e Reabilitação (STOR), o Museu Imagens do Inconsciente, a Casa das Palmeiras e o Grupo de Estudos C.G. Jung, que primaram pela conexão entre a prática clínica, a pesquisa e o ensino.

Neste sentido, a obra de Nise ganhou importante dimensão para a humanidade ao trazer à luz os dramas dos sujeitos psicóticos que se encontravam reduzidos aos rótulos de cronicidade 
demencial. Estes ressurgiram, por meio da criatividade e do acompanhamento terapêutico, como seres capazes de produzir, de interagir e de criar belíssimas obras de arte. Trata-se, portanto, de uma profunda reflexão que confrontou o universo da psiquiatria e ultrapassou os seus limites, tornando-se referência para a saúde mental, as artes, a filosofia, a antropologia e a cultura nacional.

Alguns desses aspectos foram debatidos em setembro de 2010, durante o IV Encontro de Arte \& Saúde Mental, ${ }^{1}$ realizado na Universidade do Estado do Rio de Janeiro - UERJ, que teve como título e tema $O$ paradigma estético na clínica de Nise da Silveira. Durante o Encontro, foram analisadas as interfaces da obra de Nise da Silveira com diversos campos de conhecimento. Em relação à Reforma, foi lembrado o seu pioneirismo, mas também a importância que tem para que possamos refletir sobre os atuais desafios do cuidado e da assistência no campo da saúde mental, ou seja, sua obra nos faz pensar para além da Reforma.

Observamos que há uma tendência à mitificação do nome de Nise, o que traz prejuízo ao reconhecimento de sua obra (Melo, 2005). Sendo assim, não trataremos o pensamento e as ações de Nise da Silveira a partir do entrelaçamento entre vida e obra, evitando a excessiva coerência inerente aos relatos biográficos. Pontuaremos alguns dos atos de criação de sua obra construída ao longo de várias décadas. Obra sempre aberta a reavaliações e que, aqui, será mantida em seu caráter de abertura e que se pautou rigorosamente no que afirmava Freud em relação à psicanálise: a clínica e a pesquisa coincidem.

Desde os seus primeiros atos, constata-se uma contraposição de suas criações à psiquiatria clássica e, apesar de práticas atuais situadas na chamada Reforma terem influências de sua clínica, em termos dos pressupostos reformistas gerais, entendemos sua obra para além da Reforma. Um dos elementos que justifica este para além é o paradigma estético ${ }^{2}$ no qual está baseada sua proposta clínica. Talvez essa relação com as artes tenha facilitado a mitificação de seu nome, por isso, além desta análise, focaremos os dois momentos fundantes de sua práxis, sua recusa inicial de utilizar métodos agressivos, como o eletrochoque, a lobotomia e o coma insulínico; e a criação, em 1956, da Casa das Palmeiras para enfatizar o caráter de ruptura.

${ }^{1}$ O IV Encontro de Arte \& Saúde Mental: o paradigma estético na clínica de Nise da Silveira foi organizado pelo Espaço Artaud, em parceria com o Instituto de Psicologia da UERJ e com o Núcleo de Estudo, Pesquisa e Intervenção em Saúde (NEPIS) da UFSJ, e homenageou a equipe do Museu de Imagens do Inconsciente.

${ }^{2}$ De acordo com Félix Guattari (1991 [1989]), o paradigma estético se caracteriza pela abertura e desdobramento da obra, diverso do movimento descrito por Thomas Kuhn (2007 [1989]) de manutenção paradigmática, típico das ciências normais. 


\section{Mitificação ou contribuição para a ação transformadora}

Como foi assinalado, o nome de Nise passa por um processo de mitificação que eclipsa a sua obra. Há um culto ao nome, mas quando lemos as produções de pós-graduações atuais na área de saúde mental, raramente sua obra aparece nas histórias de proposições transformadoras em psiquiatria. Esse processo, no entanto, não ocorreu por acaso, pois diversas características da médica alagoana lhe conferem um lugar diferenciado, tanto no âmbito acadêmico quanto na cultura popular: a Sociedade Brasileira para o Progresso da Ciência (SBPC, 1998) a considera um dos cinquenta maiores pesquisadores do Brasil; o Conselho Federal de Psicologia lhe atribuiu o papel de uma das pioneiras da psicologia brasileira (Melo, 2001); em 1997, a Escola de Samba Acadêmicos do Salgueiro levou para a Marquês de Sapucaí o enredo De poeta, carnavalesco e louco... todo mundo tem um pouco, tendo como último carro alegórico A barca do Sol, baseado no livro Imagens do inconsciente; e no dia 31 de outubro de 1999, durante seu cortejo fúnebre, no momento em que o caixão foi depositado na urna funerária, os tambores da Estação Primeira de Mangueira ecoaram, junto com gritos de Viva Nise e abaixo o manicômio. Desta maneira, são criadas formas variadas de reverenciar a memória, exaltando seus feitos, comemorando suas datas, caracterizando a mitificação de uma personalidade carismática.

A personalidade carismática é definida por Max Weber a partir de seus atributos de santidade, de heroísmo e como exemplo para a conduta dos outros. O carisma subentende uma qualidade incomum para uma determinada pessoa que passa a ser saudada por um grupo de seguidores. Os integrantes do círculo de adeptos passam a disputar o lugar de maior proximidade, conquistando a posição de divindade por associação. A manutenção do carisma pede uma organização das rotinas, a lembrança de acontecimentos marcantes, a criação de interesses comuns que giram ao redor da vida do líder: "Em sua forma genuína a dominação carismática é de caráter especificamente extraordinário e fora do cotidiano, representando uma relação social rigorosamente pessoal, unida à realidade carismática de qualidades pessoais e à sua corroboração" (Weber, 1944/2004, p. 197; grifo no original). O movimento de ampliação da personalidade carismática constitui uma figura e um espaço sagrados, por mais que não façam parte dos cânones de qualquer religião.

Reverenciar o nome de Nise não implica, no entanto, o estudo de sua obra. Nesse caso vemos ocorrer um processo inversamente proporcional entre a mitificação e o aprofundamento de suas ideias: em qual especialização de psiquiatria os livros de Nise são estudados? Em qual serviço instituído pela Reforma suas ideias são levadas adiante? 
O mito Nise da Silveira pode ser muito produtivo para a Reforma, pois o caráter libertário de suas ideias e a extrema delicadeza de suas proposições a faz uma intelectual altamente popular. Essa popularidade cria a ideia de que não devemos tratar as pessoas trancafiando-as, mas sim lhes dando a possibilidade de produzir por meio de atividades de reconhecido valor social. A grande aceitação da figura de Nise leva os assuntos referentes ao campo da saúde mental, antes restrito a debates entre especialistas, para um público mais amplo. Assim, o debate com a sociedade ganha um forte aliado em seu mito.

Por outro lado, esta mitificação pode ser deletéria para a Reforma, pois está se criando um forte discurso de reverência de sua figura e um parco debate de suas ideias. A primeira etapa do processo da Reforma já foi efetuada: substituir gradativamente o modelo centrado no hospital psiquiátrico por dispositivos espalhados pelo território de uma cidade, como os CAPS e os Serviços Residenciais Terapêuticos. Não podemos, entretanto, nos furtar de uma ampla discussão acerca das ideias de Nise, não para criar cópias de seu modelo de tratamento, mas simplesmente para lhe prestar uma devida homenagem: enriquecer o debate.

\section{A clínica e o paradigma estético}

Nise estipulou parâmetros para estabelecer uma clínica. Ela criou e adotou recursos para: a) avaliar e propor métodos terapêuticos; b) propor meios especiais de cuidados para as condições subjetivas dos psicóticos; c) investigar o diagnóstico e as experiências das pessoas em tratamento. Temos, assim, uma clínica aliada ao estudo dos processos psicóticos. Nesse sentido, propomos dividir a sua obra nas três dimensões:

- clínica - constituição de espaço e recursos terapêuticos: relacionais, recreativos, plásticos, dramáticos e culturais;

- pesquisa - estudo da produção criativa e artística dos frequentadores do Museu de Imagens do Inconsciente e da Casa das Palmeiras em relação à biografia e aos conteúdos inconscientes;

- ensino - orientações e supervisões clínicas, cursos de atualizações, organização do Centro de Estudos do Museu de Imagens do Inconsciente e do Grupo de Estudos C.G. Jung, além de sua produção escrita.

No âmbito da clínica, ela entendeu a ruptura psicótica como um impacto violento que abala o psiquismo, deixando o sujeito em frangalhos (Silveira, 1981). Nesse sentido, a internação nos hospícios apresenta-se como um fator que agrava a fragmentação do sujeito e de sua identidade. Sendo assim, Nise criou uma clínica para os sujeitos com diagnósticos de psicoses graves. Mais especificamente, uma 
clínica da esquizofrenia, ou melhor, das pessoas fragmentadas pelo estilhaçamento da psique e do eu, como ela mesma diria.

Para abordar as vivências que alteram a lógica do pensamento, desmembram ou metamorfoseiam os corpos, expandem ou retraem a personalidade, modificam as estruturas espaciais e temporais, e interpenetram o mundo externo e o mundo interno (Silveira, 1981; 1992; 1979/2006, Nise se valeu do pensamento de Artaud, para quem o ser tem estados inumeráveis e cada vez mais perigosos. Dessa maneira, Nise contrapõe ao poder normativo e disciplinar, apresentado pelas instituições psiquiátricas, o argumento dos inumeráveis estados do ser como forma de cada um se apresentar ao mundo (Silveira, 1989).

No entanto, esse tipo de abordagem não pode ocorrer em qualquer ambiente. Faz-se necessária a criação de condições que favoreçam a capacidade expressiva e relacional de cada sujeito. Com a finalidade de criar as condições necessárias para estabelecer o modelo clínico pautado no afeto, na livre expressão e na liberdade, Nise estabeleceu dois momentos de ruptura: a) ao recusar a utilização de métodos agressivos (Silveira, 1992); b) ao criar a Casa das Palmeiras (Silveira, 1986).

Como já foi afirmado, desde o início Nise recusou métodos como o eletrochoque, o coma insulínico e a lobotomia, contra os quais empreendeu intensos embates (Melo, 2009b). Ao se opor a essas práticas, ela tomou outro caminho, criando uma proposta clínica inovadora (Ferreira, 2010; Mello, 2009b). Através da criação da STOR, do Museu Imagens do Inconsciente e da Casa das Palmeiras, fundou uma práxis clínica original e produziu mutações (Silveira, 1992) na psiquiatria brasileira.

Em 1946, ao recusar a aplicação do eletrochoque e oferecer recursos ativos, criativos e interativos aos internos do centro psiquiátrico, estabelece um ato fundador e paradigmático de sua ruptura com o sistema psiquiátrico da época. Contra o espaço fechado, através da criatividade e da acolhida empática, janelas e portas foram se abrindo e outros espaços foram sendo criados. Neste ato, ela se contrapôs ao clinicismo - corrente nascida na Alemanha no início do século XX e que não preconizava atividades para pessoas em crise, já que deveriam ser tratadas no leito -, e ao isolamento e à segregação asilar. Em sua trajetória de mais de cinquenta anos ela continuou a enfrentar o medicalismo e o biologicismo da psiquiatria. A recusa em utilizar os instrumentos terapêuticos da época exigiu que ela lançasse mão de outras possibilidades, adotando a terapêutica ocupacional como modalidade de tratamento que pautou a sua clínica:

$\mathrm{O}$ asilo era um não lugar, um espaço desvitalizado no qual o tempo se estagnava, transformando seus habitantes em não sujeitos perambulando por um limbo existencial. $\mathrm{O}$ ateliê que Nise criou era a antítese disto: uma ilha de emoções, de relações afetivas, de expressão subjetiva, um lugar de convívio e exploração da singularidade. (Bezerra Jr., 2011, p. 14) 
Desde o início ela privilegiou recursos terapêuticos que propiciassem a livre expressão. Nos diversos ateliês e oficinas eram trabalhados os aspectos afetivos, espaciais e temporais, por um viés diverso da abordagem da psiquiatria clássica. Seu enfoque compreensivo privilegiou o acompanhamento diário em cada setor de atividades, assim como no estudo sistemático das imagens produzidas, ou seja, o estudo do "discurso em imagens" (Silveira, 1979/2006, p. 141). Dessa maneira, a abordagem de supressão dos sintomas é substituída pelo acompanhamento das tentativas de cura empreendidas pelo próprio sujeito, por meio da expressão das forças autocurativas da psique (Silveira, 1981; 1992; 1979/2006).

Em 1952, foi iniciado mais um capítulo da psiquiatria biológica, através do advento dos psicotrópicos. Nesse mesmo ano, Nise funda o Museu de Imagens do Inconsciente, a partir da exuberante produção da STOR. Trata-se, portanto, de um museu vivo, acoplado aos ateliês onde, até hoje, são realizados diversos trabalhos criativos. A STOR/Museu tornou-se um centro pluridisciplinar, cujo acervo possibilita o estudo dos processos psíquicos, acompanhados em sua singularidade por intermédio da análise das obras em paralelo aos aspectos biográficos.

Diante do aprofundamento dos estudos sobre os processos psicóticos e com a revelação da riqueza das produções de sujeitos antes considerados deteriorados, embrutecidos e dementes, ela não se deixou iludir pelo entusiasmo reinante com o advento dos neurolépticos. Através de sua prática diária nas oficinas e ateliês, ela observava e acompanhava os profundos e múltiplos processos que eram vivenciados pelos sujeitos na psicose.

Portanto, o esvaziamento destas vivências e experiências pelos psicotrópicos não poderia ser considerado, por ela, uma cura. Nise observou que, pela sedação e consequente inibição psíquica, resultante da ação dos neurolépticos, os sintomas eram apagados e os indivíduos devolvidos à sociedade, geralmente entorpecidos, apáticos, sem a mínima elaboração e integração de seus conteúdos psíquicos e sem o apoio de laços socioafetivos. Era este o estado em que saíam da internação. Logo, se a internação era mais curta, também o era o intervalo que antecedia a reinternação. Desde o início de seu trabalho, Nise se preocupou com as altas taxas de reinternações (Silveira, 1986). A partir dessas observações, começou a imaginar um espaço que pudesse funcionar como uma ponte entre o hospital e a vida na sociedade.

Nise (1992; 1979/2006) partiu da observação de que o ambiente hospitalar impede que se criem as condições necessárias para se tentar um tratamento eficaz. Sendo assim, além dos aspectos afetivos e expressivos, o ambiente propício ao tratamento deveria se pautar na liberdade. Nesse sentido, o tratamento teria como meta a reinserção do sujeito à sociedade. A reinserção do egresso não se faz, no entanto, sem dificuldades e as altas taxas de reinternação comprovam a falência do sistema psiquiátrico. Essas observações fundamentais levaram-na, em 1956, 
a inventar um espaço terapêutico pioneiro e inovador: a Casa das Palmeiras ${ }^{3}$ (Silveira, 1986; 1992).

Assim, era inaugurada uma prática de tratamento pluridimensional (Melo, 2012) que iluminou e ilustrou durante muitos anos outra perspectiva de abordar e de oferecer recursos para os sujeitos ditos psicóticos lidarem com suas vivências e inquietantes experiências. Trata-se de uma modalidade assistencial que se contrapõe radicalmente à prática dos hospícios e ao sistema de clausura, proposta que se apresenta na própria escolha do nome, Casa das Palmeiras, demonstrando os efeitos de um significante que marca uma práxis que se contrapõe à loucura como coisa médica.

A criação de condições propícias ao tratamento encontra-se estreitamente vinculada à pesquisa. $\mathrm{O}$ setor de encadernação, por exemplo, foi extremamente importante para comprovar a manutenção da inteligência e do pragmatismo, mesmo após diversos anos de internação; e, principalmente, o estudo das imagens produzidas nos ateliês de pintura e de modelagem foi importante para que Nise criasse um campo de pesquisa singular: o estudo das imagens do inconsciente. $\mathrm{O}$ estudo sistemático da produção advinda dos setores de atividades expressivas foi levado adiante no Museu Imagens do Inconsciente, comprovando a importância da afetividade no tratamento, e na Casa das Palmeiras, onde tratamento e pesquisa se mostraram eficazes aliados no processo de reinserção social (Melo, 2009a).

Diversos aspectos constituem um conjunto de elementos interligados e trabalhados cotidianamente em orientações e supervisões clínicas, servindo de base para a organização de cursos de atualização e de pesquisas: os aspectos biográficos, as condições familiares, os elementos sociais, os diversos modos de integração nas atividades, as formas de estruturação dos pensamentos, as vivências emocionais, as produções imaginárias, os relacionamentos afetivos, os materiais utilizados nas oficinas e ateliês, como também os conteúdos plasmados nas atividades expressivas.

$\mathrm{O}$ caráter indissociável entre teoria e prática pode ser percebido desde o início do trabalho desenvolvido por Nise. Inicialmente, ela abordou a produção plástica dos frequentadores dos ateliês pelo ponto de vista freudiano e, posteriormente, pela teoria junguiana (Silveira, 1968; Melo, 2007). Essa mudança de perspectiva vai

${ }^{3} \mathrm{~A}$ ressonância das ideias de Nise entre a maioria de seus colegas era mínima e ela recebeu diversas críticas pelo fato de propor a terapêutica ocupacional como legítimo método de tratamento. Dessa forma, Nise não poderia esperar a compreensão sobre a importância da criação de um espaço não hospitalar. No entanto, a parceria com alguns profissionais da área da saúde, com artistas e com o apoio da educadora Alzira Lopes Cortes, a ideia foi levada adiante e, no dia 23 de dezembro de 1956, inaugurou uma experiência piloto em psiquiatria no Brasil: a Casa das Palmeiras. 
se solidificar a partir da criação, em 1955, do Grupo de Estudos C.G. Jung e, em 1968, do Grupo de Estudos do Museu Imagens do Inconsciente, espaços de estudo, formação e transmissão de conhecimento.

A partir do aprofundamento da relação terapêutica, através da escuta de determinadas vivências e da produção plástica, Nise buscou nos estudos psicanalíticos e artísticos, referências teóricas e metodológicas para abordar os enigmas da psicose, tendo sempre como parâmetro o paradigma estético (Melo \& Ferreira, 2011).

Como já dissemos anteriormente, a abordagem de Nise se contrapõe aos pressupostos da psiquiatria clássica e, desde o seu ato fundador, rompe com a lógica manicomial. Nesse sentido, há uma convergência entre a abordagem de Nise e a proposta da Reforma. No entanto, não podemos encerrar suas propostas como reformistas.

Desde a década de 1970, várias iniciativas e experiências alternativas ao hospício surgiram no Brasil, influenciadas pela clínica proposta por Nise. No entanto, o projeto nacional da Reforma, gestado na década de 1980, teve grande influência das propostas italianas de fechamentos dos hospícios. O sistema de custeio público da assistência encontrava-se em crise, já que o grande incentivo à contratação de leitos e a promoção da internação em grande escala em clínicas particulares, trouxeram aos cofres públicos um montante de gastos exorbitante, tornando insustentável a sua manutenção. Dessa forma, a ideia da diminuição das internações surgiu como possível solução para o Ministério da Saúde. Havia o movimento da democratização do país e a insatisfação dos profissionais que denunciavam o arbítrio e as péssimas condições da assistência psiquiátrica. Os movimentos organizados dos trabalhadores da saúde, além de denúncias, formularam propostas de transformação que foram assimiladas pelo Ministério.

O modelo italiano trazia um viés centrado na referência psicossocial que rompeu com o asilo e produziu efeitos ao questionar as práticas de exclusão (Barros, Nicácio \& Amarante, 1997). Por esta influência, a referência psicossocial representa um foco mais hegemônico do arcabouço discursivo do modelo atual da Reforma. Trata-se de um projeto de Estado, nascido do movimento pela transformação da assistência em psiquiatria e instituído pelo Ministério da Saúde, sendo aprovado no parlamento. Mas há um movimento embalado pelo desejo daqueles que se opuseram ao status quo da psiquiatria tradicional e que iniciaram as práticas transformadoras há muito tempo. Para estes, a ideia de reforma aponta para perspectivas mais avançadas em termos de conceituação e de práticas assistenciais. Como diz Amarante (apud Yusui, 2010):

seria poder transformar as relações que a sociedade, os sujeitos e as instituições estabeleceram com a loucura, com o louco e com a doença mental, conduzindo tais relações no sentido da superação do estigma, da segregação, da desqualificação dos sujeitos ou, ainda, no sentido de estabelecer com a loucura uma relação de coexistência, de troca, de solidariedade, de positividade e de cuidados. (p. 104) 
Apesar de pouco referida nos discursos universitários e na produção técnico-política da Reforma, a clínica de Nise é o que, historicamente, temos como paradigma dos dispositivos terapêuticos propostos para a transformação institucional da psiquiatria brasileira, ou seja, trata-se de uma referência para as práticas transformadoras em saúde mental. É bom lembrar que, no curto governo de Janio Quadros, e a pedido deste, Nise apresentou, em 1961, um projeto de transformação dos hospícios brasileiros, que ficou engavetado com a renúncia do presidente (Silveira, 1979).

\section{Conclusão}

A obra de Nise é composta pela articulação entre a elaboração de uma proposta clínica, do desenvolvimento de importantes pesquisas e da organização de espaços de ensino. Seus textos e sua prática estão imbuídos pelo sensível e pela criatividade, caracterizando uma práxis estruturada pelo paradigma estético (Melo, 2011b). Além disso, se opôs de maneira ferrenha ao sistema opressivo do hospício e, em seu ato fundador e em sua vida de criações consideradas pioneiras, a rebeldia e a recusa de aceitar o estabelecido estão presentes.

Temos observado que as proposições metodológicas e as elaborações teóricas que desenvolveu para sustentar a sua práxis são pouco conhecidas, seja no âmbito das universidades seja nas discussões da Reforma. Podemos afirmar que ela nunca buscou resgatar os princípios clássicos da instituição psiquiátrica. Ao contrário, rompeu de maneira radical com o modelo disciplinar, com as propostas biologicistas e com as práticas de exclusão social. A teoria e a prática de Nise estão, assim, além de qualquer proposta reformista.

As várias discussões surgidas a partir da consciência de que o asilo psiquiátrico era violento e que a loucura não poderia ser aí confinada e reduzida ao esquecimento, foram ganhando espaço e passaram a circular junto com as lutas políticas contra as injustiças e a opressão em nosso país. Temos, aí, um ideal político que vai muito além de programas terapêuticos. Quando participamos dos encontros, manifestações, comemorações em espaços públicos, com artistas, com vários grupos de frequentadores da chamada saúde mental, com familiares e com lideranças políticas; quando a TV produz novelas e reportagens, discutindo a questão da loucura e das várias possibilidades de lidar com a chamada doença mental, concluímos que há, aí, os efeitos desta reflexividade (Giddens, 1991) produzida no bojo da Reforma. E, com frequência, o nome de Nise é citado, nos discursos, nos poemas, nas expressões plásticas e nas canções libertárias.

Portanto, revisitar o momento histórico da psiquiatria contra a qual Nise se posicionou, e analisar a trajetória de construção de um novo campo clínico, de 
pesquisa e de ensino, poderá trazer contribuições para repensar as atuais práticas de cuidado, tratamento e reinserção em saúde mental.

\section{Referências}

Avellar, J. C. (2001 jan.fev.). A sabedoria que a gente não sabe. Cinemais, 27, 179-203.

Avellar, J. C. (2011). Na fronteira entre a saúde e a não saúde. In Melo, W. \& Ferreira, A. P. (Orgs.). A sabedoria que a gente não sabe (pp. 95-105). Coleção Arte \& Saúde Mental 2. Rio de Janeiro: Espaço Artaud.

Barros, D. D.; Nicácio, F.; Amarante, P. (1997). Franco Basaglia e la riforma psichiatrica brasiliana. Rio de Janeiro: DIALOGHI/UERJ.

Bezerra Jr., B. (2011). Os sentidos da arte na atenção à Saúde Mental: considerações sobre o cenário pós-manicomial. In Melo, W. \& Ferreira, A. P. (Orgs.). A sabedoria que a gente não sabe (pp. 14-24). Coleção Arte \& Saúde Mental 2. Rio de Janeiro: Espaço Artaud.

Carvalho, S. M. M. de; Amparo, P. H. M. (2006 mar.). Nise da Silveira: a mãe da humana-idade. Revista Latinoamericana de Psicopatologia Fundamental, São Paulo, IX(1), 126-137.

Ferreira, A. P. (1999). O migrante na rede do outro: ensaios sobre alteridade e subjetividade. Rio de Janeiro: Te Corá.

Ferreira, A. P. (2010). Nise: um percurso para além da reforma. IV Encontro Arte \& Saúde Mental: o paradigma estético na clínica de Nise da Silveira. Rio de Janeiro, Universidade do Estado do Rio de Janeiro - UERJ.

Giddens, A. (1991). As consequências da modernidade. São Paulo: Unesp.

Guattari, F. (1991). As três ecologias. Campinas: Papirus. (Trabalho original publicado em 1979).

Kuhn, T. (2007). A estrutura das revoluções científicas. São Paulo: Perspectiva. (Trabalho original publicado em 1962).

Mello, L. C. (Org.). (2009). Nise da Silveira. Rio de Janeiro: Beco do Azougue.

Melo, W. (2001). Nise da Silveira. Rio de Janeiro/Brasília: Imago/CFP.

Melo, W. (2004). O social, o mítico e o místico. Cinemais: memória, história e identidade, 37, 9-77.

Melo, W. (2005). Ninguém vai sozinho ao paraiso: o percurso de Nise da Silveira na psiquiatria do Brasil. Tese de Doutorado. Rio de Janeiro: Universidade do Estado do Rio de Janeiro.

Melo, W. (2007). Será o Benedito? Livros à espera de improváveis leitores. Mnemosine, 3(1), 41-65.

Melo, W. (2009a). O terapeuta como companheiro mítico: ensaios de psicologia analítica. Rio de Janeiro: Espaço Artaud.

Melo, W. (2009b). Nise da Silveira e o campo da Saúde Mental (1944-1952): contribuições, embates e transformações. Mnemosine, 5, 30-52.

Melo, W. (2010a). Nise da Silveira, Antonin Artaud e Rubens Correa. Gerais: Revista Interinstitucional de Psicologia, 2, 182-191. 
Melo, W. (2010b). Nise da Silveira, Fernando Diniz e Leon Hirszman: política, sociedade e arte. Psicologia USP, 21, 633-652.

Melo, W. (2011a). O efeito dominó: a relação entre a obra de Nise da Silveira e a arte concreta no Brasil. In Melo, W. \& Ferreira, A. P. (Orgs.). A sabedoria que a gente não sabe (pp. 79-94). Rio de Janeiro: Espaço Artaud.

Melo, W. (2011b). Da Nau dos Insensatos ao Círculo Antropológico: a obra de arte em História da loucura de Michel Foucault. Cadernos Brasileiros de Saúde Mental, 3(6), 65-88.

Melo, W. (2012). Oswaldo dos Santos. Rio de Janeiro: Fundação Miguel de Cervantes/Fundação Biblioteca Nacional.

Melo, W. \& Ferreira, A. P. (Orgs.). (2011). A sabedoria que a gente não sabe. Coleção Arte \& Saúde Mental 2. Rio de Janeiro: Espaço Artaud.

SBPC (1998). Cientistas do Brasil. São Paulo: SBPC.

Silveira, N. da (1968). Jung: vida e obra. Rio de Janeiro: Paz e Terra.

Silveira, N. da (1979). Terapêutica ocupacional: teoria e prática. Rio de Janeiro: Casa das Palmeiras.

Silveira, N. da (1981). Imagens do inconsciente. Rio de Janeiro: Alhambra.

Silveira, N. da (1986). Casa das Palmeiras: a emoção de lidar. Rio de Janeiro: Alhambra.

Silveira, N. da (1989). Um homem em busca do seu mito. In Lucchesi, M. (Org.). Artaud: a nostalgia do mais (pp. 9-23). Rio de Janeiro: Numen.

Silveira, N. da (1992). O mundo das imagens. São Paulo: Ática.

Silveira, N. da (2006, mar.). Retrospectiva de um trabalho vivido no Centro Psiquiátrico Pedro II. Revista Latinoamericana de Psicopatologia Fundamental, São Paulo, IX(1), 138-150. (Trabalho original publicado em 1979).

Weber, M. (2004). A ética protestante e o “espírito” do Capitalismo. São Paulo: Companhia das Letras. (Trabalho original publicado em 1944).

Yusui, S. (2010). Rupturas e encontros: desafios da Reforma Psiquiátrica Brasileira. Rio de Janeiro: Fiocruz.

Resumos

(Clinical work, research and teaching: Nise da Silveira and mutations in Brazilian psychiatry)

The objective of this paper is to discuss the absence of the work of Nise da Silveira from the academic literature. As an introduction, we will describe two paradigmatic acts of hers. First, upon returning to the hospice in 1946 she refused to apply electroconvulsive therapy, had some of the infirmary beds taken out and created space for developing creative and expressive activities. Second, she designed and implemented an outdoor space called Casa das Palmeiras for treating severe cases of psychosis. Both 
these acts contradicted the clinicism and segregation practiced in asylums. In Silveira's professional practice, clinical and research were inseparable and she introduced the importance of aesthetic factors. This brought about mutations in Brazilian psychiatry and went far beyond the simple idea of reform. Studying her work is a way to counteract the mystification of her name. We are aware that a paper on such an important legacy is very limited, but we hope it will call attention to Nise da Silveira's work and generate interest in it.

Key words: Nise da Silveira, clinic, research, mutations

(Clinique, recherche et enseignement: Nise da Silveira et les Mutations de la Psychiatrie Brésilienne)

Le travail de Nise da Silveira s'appuie sur deux axes paradigmatiques. De retour à l'hospice en 1946, elle refuse d'appliquer la thérapie par électrochocs, élimine une partie des lits d'infirmerie et crée des espaces pour le développement d'activités créatives et expressives. Le second axe porte sur la création d'un espace extérieur, la Casa das Palmeiras, réservé aux cas de psychose graves. Ces axes contredisent à la fois le clinicisme et la ségrégation en asile. Dans sa pratique, recherche et clinique étaient inséparables et l'accent était mis sur le paradigme esthétique, produisant des mutations en psychiatrie qui allaient au-delà de l'idée de la réforme. Cet article soutient d'ailleurs que connaître son travail est un moyen de contrer la mystification de son nom. Il va de soi que cet article ne suffit pas pour examiner l'héritage de son travail. Il s'agit donc d'indiquer et de diffuser des éléments choisis arbitrairement pour susciter l'intérêt à leur étude.

Mots clés: Nise da Silveira, clinique, recherche, mutations

(Investigación, clínica y enseñanza: Nise da Silveira y mutaciones en la psiquiatría brasileña)

El trabajo de Nise da Silveira es enfocado en dos actos paradigmáticos. Al regresar al hospicio en 1946, se negó a aplicar la terapia electroconvulsiva, retiró camas de la enfermería y creó espacios para el desarrollo de actividades creativas y expresivas. El segundo fue la creación de un espacio externo, la Casa de las Palmeras, para sujetos con psicosis graves. Estos actos se contraponen tanto al clinicismo como a la segregación asilar. En su práctica, la investigación y la clínica eran inseparables, con fuerte presencia del paradigma estético, lo que produjo mutaciones en la psiquiatría brasileña, superando la idea de reforma. Conocer su trabajo es una manera de contraponerse a su mistificación. Conocemos los límites de un artículo para examinar el legado de su obra. Aqui se trata de señalar y vehicular elementos arbitrariamente escogidos para generar interés en su estudio.

Palabras clave: Nise da Silveira, clínica, investigación, mutaciones

(Klinik, Forschung und Bildung: Nise da Silveira und die Veränderungen in der 
brasilianischen Psychiatrie)

Hier soll auf die Abwesenheit des Werks von Nise da Silveira in den akademischen Reihen aufmerksam gemacht werden. Um ihre Bedeutsamkeit aufzuzeigen, wird ihr Werk in zwei paradigmatischen Abhandlungen dargestellt: Die Erste, in der nach der Verweigerung die ECT anzuwenden, die Betten aus der Krankenstation entfernt wurden, um einen Raum für Beschäftigungs- und Ausdrucksaktivitäten einzurichten. Die Zweite ist die Schaffung eines Raumes außerhalb des Hospizes Casa das Palmeiras für besonders schwere Psychosefälle. Diese Handlungen stellen sich sowohl dem klinischen Behandeln wie auch der Segregation in Heimen entgegen. Es versteht sich, dass Forschung und klinische Behandlung in der Praxis untrennbar waren und ein starkes ästhetisches Paradigma aufgewiesen haben. Dies führte zu Veränderungen in der brasilianischen Psychiatrie, weit über die Grenzen einer Reform hinaus. Sein Werk kennenzulernen, ist eine Form, sich seiner Mystifizierung entgegenzustellen. Die Grenzen eines Beitrages zur Untersuchung des Vermächtnisses ihres Werkes sind bekannt. Es geht hier darum, einige willkürlich ausgesuchte Elemente hervorzuheben und in Umlauf zu bringen und das Interesse an ihrer Untersuchung zu wecken.

Schlüsselwörter: Nise de Silveira, Klinik, Forschung, Veränderungen

Citação/Citation: Melo, W., Ferreira, A. P. (2013, dezembro). Clínica, pesquisa e ensino: Nise da Silveira e as mutações na Psiquiatria Brasileira. Revista Latinoamericana de Psicopatologia Fundamental, 16(4), 555-569.

Editor do artigo/Editor: Manoel Tosta Berlinck

Recebido/Received: 28.9.2012/ 9.28.2012 Aceito/Accepted: 15.12.2012/12.15.2012

Copyright: (C) 2009 Associação Universitária de Pesquisa em Psicopatologia Fundamental/ University Association for Research in Fundamental Psychopathology. Este é um artigo de livre acesso, que permite uso irrestrito, distribuição e reprodução em qualquer meio, desde que o autor e a fonte sejam citados / This is an open-access article, which permits unrestricted use, distribution, and reproduction in any medium, provided the original authors and sources are credited. 
Financiamento/Funding: Os autores declaram não terem sido financiados ou apoiados / The authors have no support or funding to report.

Conflito de interesses/Conflict of interest: Os autores declaram que não há conflito de interesses / The authors declare that has no conflict of interest.

\section{Walter Melo}

Professor Adjunto da Universidade Federal de São João del-Rei - UFSJ (São João del-Rei, MG. Br); Professor do Mestrado de Psicologia na mesma universidade; Coordenador do Núcleo de Estudo, Pesquisa e Intervenção em Saúde - NEPIS (São João de-Rei, MG, Br); Sócio fundador do Espaço Artaud (São João del-Rei, MG, Br); e autor dos livros: Nise da Silveira (Imago/ CFP, 2001) e $O$ terapeuta como companheiro mítico: ensaios de psicologia analítica (Espaço Artaud, 2009a).

Rua Idilberto de Andrade, 261 - Cascalho

36325-000 Tiradentes, MG, Br

e-mail:wmelojr@gmail.com

\section{Ademir Pacelli Ferreira}

Professor Associado do Instituto de Psicologia da Universidade do Estado do Rio de Janeiro - IP/UERJ (Rio de Janeiro, RJ, Br); Procientista; Docente da Pós-Graduação em Psicanálise; Supervisor de projetos de Estágio, Iniciação Científica e Especialização junto ao CAPS-UERJ; autor do livro, O migrante na rede do outro (Te Corá, 1999); Coorganizador de vários livros e autor de vários artigos sobre clínica, psicopatologia e Saúde Mental; Membro da Associação Universitária de Pesquisa em Psicopatologia Fundamental - AUPPF (São Paulo, SP, Br).

Rua Uruguai, 449B/402 - Tijuca

20510-060 Rio de Janeiro, RJ, Br.

e-mail: ademirpacelli@uol.com.br 